\title{
Modelling growth curve of Eastern spot-billed ducks (Anas zonorhyncha) raised in Vietnam
}

\author{
N.H. Thinh', B.H. Doan', P.K. Dang ${ }^{1}$, N.X. Canh², N.T.C. Giang ${ }^{1}$, L.Q. Minh ${ }^{3}$ and D.N. Do ${ }^{4,5,6}$ \\ Vietnam National University of Agriculture, \\ ${ }^{1}$ Faculty of Animal Science, ${ }^{2}$ Faculty of Biotechnology, Hanoi 100000 , Vietnam \\ ${ }^{3}$ Ministry of Science and Technology, Hanoi, 100000, Vietnam \\ ${ }^{4}$ Duy Tan University, Institute of Research and Development, Danang 550000, Vietnam \\ ${ }^{5}$ Dalhousie University, Department of Animal Science and Aquaculture, Truro, NS B2N 5E3, Canada
}

KEY WORDS: body weight, Eastern spot-billed duck, growth curve, Vietnam

Received: 21 January 2021

Revised: 2 March 2021

Accepted: 4 March 2021

${ }^{6}$ Corresponding author:

e-mail: dongocduy1@duytan.edu.vn

\begin{abstract}
The Eastern spot-billed ducks (Anas zonorhyncha) are raised as backyard duck in Vietnam. Improvement of the growth performance of this breed is important for duck production in rural areas in Vietnam. Little is known about the performance and growth curves of this breed. In this study, six growth models (Gompertz, Brody, Logistic, Richards, Bridges and Janoschek) were used for a modelling growth curve. The body weight of 92 ducks was recorded weekly from the $1^{\text {st }}$ to the $14^{\text {th }}$ week of age. The minpack.Im package in $\mathrm{R}$ software was used for fitting the models, and Akaike's information criterion (AIC) and Bayesian information criterion (BIC) were used for model comparison. Based on their criteria, the Gompertz and Brody models were the best and the worst ones, respectively, regardless of sexes. Estimated asymmetric weights (a) ranged from $1179 \pm 9.24 \mathrm{~g}$ (Logistic model) to $1397 \pm 26.3 \mathrm{~g}$ (Brody model) for males and from $1048 \pm 6.92 \mathrm{~g}$ (Logistic model) and $1222 \pm 19.28 \mathrm{~g}$ (Brody model) for females, respectively. Age at inflection point was estimated from 3.58 to 4.58 weeks for males and from 3.48 to 4.46 weeks for females, respectively. The growth patterns were different between males and females. So, the possibility of using the Gompertz growth model for modelling the growth of Eastern spot-billed ducks was shown. Obtained information on the growth characteristics of Eastern spot-billed ducks might be used for management strategies and further genetic or genomic research.
\end{abstract}

\section{Introduction}

According to Food and Agriculture Organization of the United Nations (FAO) statistics, the population of ducks in the world was esteemed as $1.17 \mathrm{mln}$ and it was produced approximately $3235471 \mathrm{t}$ of duck meat in 2019 (FAOSTAT, 2021). Vietnam produced approximately $82277 \mathrm{t}$ of duck meat in 2019 and was the third-largest duck producer in the world (FAOSTAT, 2021). In Vietnam, ducks play an important role as a food source (meat and eggs), especially in the Red River and Mekong Deltas. Duck meat in comparison to pork, beef and chicken meat is usually cheaper and therefore it is affordable for farmers in the rural area. The duck and its meat are also important for Vietnamese culture. Importantly, duck raising is often connected with fish farming, which could provide sustainable development for small farmers (Minh et al., 2006). Recently, we have also indicated a high level of genetic diversity in domestic duck populations in Vietnam (Pham et al., 2021). 
In livestock production, characterization of growth contributes to better management and feeding practices to maximize productivity. Different mathematical models have been applied to describe animal growth and non-linear approachtable growth in many species. In poultry, the Gompertz, Brody, Logistic, Bridges, Janoschek and Richards are the most common non-linear models (Kaplan and Gürcan, 2018). However, the growth curve of different duck breeds was characterised only in few studies (Knížetová et al., 1995; Maruyama et al., 2001; Vitezica et al., 2010; Kaewtapee et al., 2018). None of such a research was conducted in Vietnam; therefore, the aim of this study was to compare six commonly used mathematical models (Gompertz, Brody, Logistic, Richards, Bridges and Janoschek) for describing the growth curve of Eastern spotbilled duck (Anas zonorhyncha) in Vietnam.

\section{Material and methods}

\section{Resource population}

In total, 92 ducks (43 males and 49 females) were used in the current study. Animals were raised in floor pens at the Breeding Center of the Vietnam National University of Agriculture (Hanoi, Vietnam). Ducks were fed commercial diets ad libitum according to the guidelines of the National Institute of Animal Science (TCN654, 2005) (Table 1).

Table 1. The diets according to two different growth periods

\begin{tabular}{lcc}
\hline Indices & Week 0-4 & Week 5-14 \\
\hline Gross energy, kcal/kg & 2900 & 2800 \\
Protein, \% & 20.0 & 18.0 \\
Ash, \% & 3.50 & 4.50 \\
Calcium, \% & 1.05 & 0.95 \\
Phosphorus, \% & 0.52 & 0.41 \\
Methionine, \% & 0.81 & 0.65 \\
Lysine, \% & 1.15 & 0.84 \\
\hline
\end{tabular}

In weeks 1-4, ducks were raised at the density of $15 \mathrm{birds} / \mathrm{m}^{2}$ with the light illumination of $24 \mathrm{~h} /$ day and temperature of $28-35^{\circ} \mathrm{C}$. In weeks $5-14$, ducks were raised at the density of $6 \mathrm{birds} / \mathrm{m}^{2}$, the light illumination of $16 \mathrm{~h} /$ day and temperature of 20-35 ${ }^{\circ} \mathrm{C}$. Body weights (BW) were measured individually from the $1^{\text {st }}$ week to the $14^{\text {th }}$ week of age. The influences of week, sex and their interactions on BW were tested using a linear model in R software (R Development Core Team, 2011):

$$
\mathrm{BW}_{i j k}=\mu+\mathrm{w}_{i}+\mathrm{s}_{j}+\mathrm{w}_{i} \times \mathrm{s}_{j}+e_{i j k},
$$

where: $\mathrm{BW}_{i j k}-$ vector of body weight at week $i$ of animal $k$ with sex $j, \mu$ - overall mean, $\mathrm{w}_{i}-$ vector of fixed effect of week $i$ (level 1:14), $\mathrm{s}_{j}$ - vector of fixed effect of sex $j$ (level 1:2), $\mathrm{w}_{i k} \times_{k} \mathrm{~s}_{j}$ - interaction between week $i$ and $\operatorname{sex} j$ (level 1:28), and $e_{i j k}$-random error. Significant effects were tested using the anova function in R software (R Development Core Team, 2011) and were declared at $P<0.05$.

\section{Growth modelling and evaluations}

Six different growth models (Gompertz, Brody, Logistic, Richards, Bridges and Janoschek) were used for modelling growth curves of males and females separately (Table 2). Body weight was fitted as a function of the evaluated week using the nlsLM function in the minpack.lm package in R software (R Development Core Team, 2011), respectively. The Akaike's information criterion (AIC) and Bayesian information, which are suitable for comparing the non-linear models, were used to assess the model performance. Pearson's correlation between predicted $\mathrm{BW}$ and measured $\mathrm{BW}$ was calculated using the cor function in the R software (R Development Core Team, 2011). The prediction bias was computed as the coefficient in a linear regression of the predicted BW in measured BW.

Table 2. Growth models used in the study

\begin{tabular}{|c|c|c|c|}
\hline Model & Equation & $\begin{array}{l}\text { Age } \\
\text { at inflection }\end{array}$ & $\begin{array}{l}\text { Weight } \\
\text { of inflection }\end{array}$ \\
\hline Logistic & $B W_{t}=\frac{a}{\beta \times\left(1+e^{-k t}\right)}$ & $\frac{a}{2}$ & $-\frac{\ln \left(\frac{1}{\beta}\right)}{k}$ \\
\hline Gompertz & $B W_{t}=\alpha \times e^{-\beta \times e^{-k t}}$ & $\frac{a}{e}$ & $\frac{\ln (\beta)}{k}$ \\
\hline Brody & $B W_{t}=\alpha \times\left(1-\beta \times e^{-k t}\right)$ & - & - \\
\hline Bridges & $B W_{t}=B W_{0}+a \times\left(1-e^{-k t^{m}}\right)$ & - & - \\
\hline Janoschek & $B W_{t}=a-\left(a-B W_{0}\right) \times e^{-k t^{m}}$ & - & - \\
\hline Richards & $B W_{t}=\frac{a}{\left(1-\beta \times e^{-k t}\right)^{\frac{1}{m}}}$ & $\frac{a}{(m+1)^{\frac{1}{m}}}$ & $-\frac{\ln \left(\frac{\bar{\beta}}{\beta}\right)}{k}$ \\
\hline
\end{tabular}

$\mathrm{BW}_{\mathrm{t}}$ - body weight in $\mathrm{kg}$ at the time $\mathrm{t} ; \mathrm{BW}_{0}$ - initial body weight in $\mathrm{kg}$; $a$ - mature body weight in $\mathrm{g} ; \mathrm{t}$ - age in weeks; $\beta, \mathrm{k}$ and $\mathrm{m}$ - parameters specific for the function: $\beta$ characterizes the first part of growth before the point of inflection, $\mathrm{k}$ describes the second part in which growth rate decreases until the animal reaches the asymptotic or mature weight (a) and $m$ is the shape parameter determining the position of the curve point inflection; $\mathrm{e}-$ the Euler's number ( 2.71828)

\section{Results}

\section{Body weight measurement and model comparison}

Arithmetic means with standard errors of BW, and the coefficient of covariation are shown in Table 3. Body weight increased from 
$71.5 \pm 2.25$ to $1221 \pm 22.4 \mathrm{~g}$ in males and from $72.7 \pm 1.9$ to $1073 \pm 15.57 \mathrm{~g}$ in females, respectively. Males had higher BW than females, except for the first week from birth. It was significantly affected by week $(P<0.001)$, sex $(P<0.001)$ and their

Table 3. Summary of body weights by time and sex

\begin{tabular}{|c|c|c|c|c|c|c|}
\hline \multirow{2}{*}{ Week } & \multicolumn{3}{|c|}{ Male } & \multicolumn{3}{|c|}{ Female } \\
\hline & $\mathrm{N}$ & BW, $g$ & CV, $\%$ & $\mathrm{~N}$ & BW, g & $\mathrm{CV}, \%$ \\
\hline 1 & 43 & $71.5 \pm 2.25$ & 20.6 & 49 & $72.7 \pm 1.90$ & 18.3 \\
\hline 2 & 43 & $195 \pm 5.84$ & 19.6 & 49 & $190 \pm 5.40$ & 19.9 \\
\hline 3 & 43 & $337 \pm 9.82$ & 19.1 & 49 & $312 \pm 8.64^{*}$ & 19.4 \\
\hline 4 & 43 & $532 \pm 13.4$ & 16.6 & 49 & $474 \pm 11.9^{*}$ & 17.6 \\
\hline 5 & 43 & $695 \pm 15.2$ & 14.3 & 49 & $623 \pm 14.1^{*}$ & 15.9 \\
\hline 6 & 43 & $830 \pm 18.5$ & 14.6 & 49 & $757 \pm 15.5^{*}$ & 14.31 \\
\hline 7 & 43 & $934 \pm 18.6$ & 13.0 & 49 & $862 \pm 16.9^{*}$ & 13.8 \\
\hline 8 & 43 & $988 \pm 17.1$ & 11.4 & 49 & $894 \pm 15.2^{*}$ & 11.9 \\
\hline 9 & 43 & $1062 \pm 19.5$ & 12.1 & 49 & $960 \pm 15.2^{*}$ & 11.1 \\
\hline 10 & 43 & $1103 \pm 19.7$ & 11.7 & 49 & $992 \pm 14.6^{*}$ & 10.3 \\
\hline 11 & 43 & $1150 \pm 20.4$ & 11.6 & 49 & $1030 \pm 13.9^{*}$ & 9.47 \\
\hline 12 & 43 & $1167 \pm 20.6$ & 11.6 & 49 & $1046 \pm 15.1^{*}$ & 10.1 \\
\hline 13 & 43 & $1199 \pm 21.5$ & 11.7 & 49 & $1057 \pm 14.4^{*}$ & 9.56 \\
\hline 14 & 43 & $1221 \pm 22.4$ & 12.0 & 49 & $1073 \pm 15.5^{*}$ & 10.1 \\
\hline
\end{tabular}

$\mathrm{N}$ - number of animals, BW - body weight (expressed as mean $\pm \mathrm{SE}), \mathrm{CV}$ - coefficient of variation, * indicates the significant difference between the body weight of males and females $(P<0.05)$ at each week interaction $(P<0.001)$. Coefficients of variation varied among weeks, and the highest values were found in weeks 1-3 for both males and females (Table 3). The goodness of fit of the six models is shown in Table 4. Based on the AIC and BIC criteria, the Gompertz was the best model for both males and females. The Brody model was the worst as it had the highest AIC and BIC in both males and females. The Gompertz and Brody models also had the lowest and highest mean square errors, respectively. The three-parameter (Gompertz, Brody and Logistic) and four-parameter (Richards, Bridges and Janoschek) models had a similar performance. A similar performance was reported also for Bridges and Janoschek models in both sexes. Pearson's correlations between predicted BW and measured BW were high for all models as the values of correlations were always higher than 0.99 in all models. Similarly, the bias of prediction of BW was very close to one, indicating their models could be used to predict BW in ducks. The Brody model had the lowest correlation values of prediction in both males and females, while the Richards and Gompertz models had the highest correlation values for female data. The actual BW and the growth curves from the best and the worst models are shown in Figure 1.
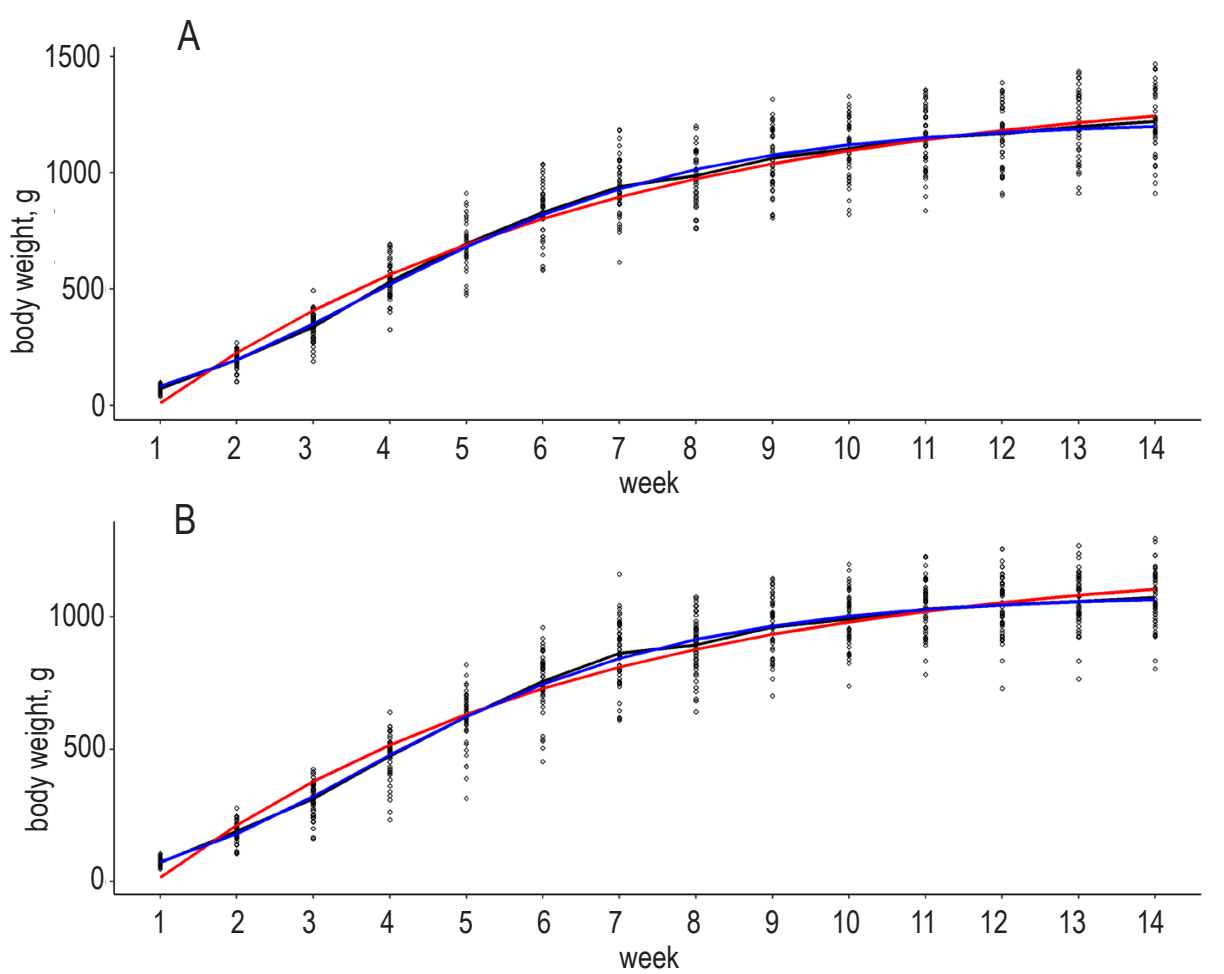

Figure 1. The growth curve of male and female chickens for the best and the worst model in male (A) and female (B) ducks The black dots indicate the body weights of each animal. The black, blue and red lines show the mean of actual body weights and the growth curve of the best (Gompertz) and the worst (Brody) model, respectively. 
Table 4. The goodness of fit of growth curve models for body weights in males and females

\begin{tabular}{|c|c|c|c|c|c|c|c|c|c|c|c|}
\hline \multirow{2}{*}{ Model } & \multirow{2}{*}{$\begin{array}{l}\text { Degree of } \\
\text { freedom }\end{array}$} & \multicolumn{5}{|l|}{ Male } & \multicolumn{5}{|c|}{ Female } \\
\hline & & $\overline{A I C}$ & $\mathrm{BIC}$ & MSE & Bias & Cor & $\overline{A I C}$ & $\mathrm{BIC}$ & MSE & Bias & Cor \\
\hline Logistic & 4 & 7433 & 7450 & 13295 & 0.9740 & 0.9968 & 8209 & 8227 & 9110 & 0.9816 & 0.9980 \\
\hline Gompertz & 4 & 7394 & 7412 & 12471 & 0.9948 & 0.9994 & 8180 & 8199 & 8737 & 0.9991 & 0.9996 \\
\hline Brody & 4 & 7436 & 7454 & 13378 & 0.9923 & 0.9961 & 8260 & 8278 & 9813 & 0.9895 & 0.9948 \\
\hline Bridges & 5 & 7397 & 7419 & 12488 & 0.9986 & 0.9993 & 8186 & 8208 & 8777 & 0.9988 & 0.9994 \\
\hline Janoschek & 5 & 7397 & 7419 & 12488 & 0.9986 & 0.9993 & 8186 & 8208 & 8777 & 0.9988 & 0.9994 \\
\hline Richards & 5 & 7396 & 7418 & 12471 & 0.9948 & 0.9994 & 8182 & 8205 & 8737 & 0.9991 & 0.9996 \\
\hline
\end{tabular}

AIC - Akaike's information criterion, BIC - Bayesian information criterion, MSE - mean square errors, Bias - coefficient of a linear regression of predicted body weights on actual body weights, Cor - Pearson's correlation between predicted and actual body weights

Table 5. Estimated parameters for growth curve models in Eastern spot-billed ducks

\begin{tabular}{|c|c|c|c|c|c|c|c|c|}
\hline Model & Sex & $a, g$ & $\beta$ & k, g/week & $\mathrm{m}$ & $\mathrm{BW}_{0}$ & AIP, week & WIP, g \\
\hline \multirow[t]{2}{*}{ Logistic } & male & $1179 \pm 9.24$ & $14.0 \pm 1.15$ & $0.58 \pm 0.02$ & & & 4.58 & 590 \\
\hline & female & $1048 \pm 6.92$ & $14.3 \pm 1.04$ & $0.60 \pm 0.02$ & & & 4.46 & 524 \\
\hline \multirow[t]{2}{*}{ Gompertz } & male & $1221 \pm 11.6$ & $3.93 \pm 0.19$ & $0.38 \pm 0.01$ & & & 3.58 & 434 \\
\hline & female & $1082 \pm 8.69$ & $3.95 \pm 0.17$ & $0.39 \pm 0.01$ & & & 3.48 & 398 \\
\hline \multirow[t]{2}{*}{ Brody } & male & $1397 \pm 26.3$ & $1.18 \pm 0.02$ & $0.17 \pm 0.01$ & & & & \\
\hline & female & $1222 \pm 19.3$ & $1.18 \pm 0.02$ & $0.18 \pm 0.01$ & & & & \\
\hline \multirow[t]{2}{*}{ Bridges } & male & $1235 \pm 37.6$ & & $0.06 \pm 0.01$ & $1.60 \pm 0.09$ & $-16.3 \pm 27.2$ & & \\
\hline & female & $1052 \pm 25.0$ & & $0.05 \pm 0.01$ & $1.73 \pm 0.08$ & $15.6 \pm 19.3$ & & \\
\hline \multirow[t]{2}{*}{ Janoschek } & male & $1219 \pm 16.1$ & & $0.06 \pm 0.01$ & $1.60 \pm 0.09$ & $-16.3 \pm 27.2$ & & \\
\hline & female & $1067 \pm 10.0$ & & $0.05 \pm 0.01$ & $1.73 \pm 0.08$ & $15.6 \pm 19.3$ & & \\
\hline \multirow[t]{2}{*}{ Richards } & male & $1221 \pm 11.9$ & $1.5 e-04 \pm 0.004$ & $0.38 \pm 0.01$ & $3.7 e-05 \pm 0.001$ & & 3.58 & 449 \\
\hline & female & $1082 \pm 11.4$ & $3.9 e-03 \pm 0.57$ & $0.39 \pm 0.03$ & $9.9 \mathrm{e}-04 \pm 0.14$ & & 3.48 & 398 \\
\hline
\end{tabular}

$\mathrm{BW}_{0}$ - initial body weight in $\mathrm{g} ; \mathrm{a}$ - mature body weight; $\beta, \mathrm{k}$ and $\mathrm{m}$ - parameters specific for the function: $\beta$ characterizes the first part of growth before the point of inflection, $k$ describes the second part in which growth rate decreases until the animal reaches the asymptotic or mature weight (a), and $\mathrm{m}$ is the shape parameter determining the position of the curve point inflection; AIP - age at the inflection, WIP - weight at inflection

\section{Estimated growth parameters}

Estimated growth parameters are shown in Table 5. Estimated asymmetric weights $(\alpha)$ ranged from $1179 \pm 9.24 \mathrm{~g}$ (Logistic model) to $1397 \pm$ $26.3 \mathrm{~g}$ (Brody model) for males and from $1048 \pm$ $6.92 \mathrm{~g}$ (Logistic model) and $1222 \pm 19.3 \mathrm{~g}$ (Brody model) for females, respectively. Estimated mature growth rates $(\mathrm{k})$ were similar between males and females in all models. The highest $\mathrm{k}$ values were obtained from the Logistic model, while the lowest values were observed in the Janoschek and Bridges models, regardless of sex. The values $\beta$ and the shape parameters value $(\mathrm{m})$ were also varied among models and sexes. The females had lower estimated age and weight at inflection point than the males in all models (Table 5). Age at inflection point was estimated in weeks $3.58-4.58$ for males and in weeks $3.48-4.46$ for females, respectively.

\section{Discussion}

The Eastern spot-billed duck is a species of dabbling duck distributed in East and Southeast Asia (Cherry and Morris, 2008). Body weight of the Eastern spot-billed duck in the mentioned study ranged from 790 to $1500 \mathrm{~g}$ (Cherry and Morris, 2008), but it was slightly lower than of Shan Ma ducks (1 $260 \pm 110 \mathrm{~g}$ at 110 days (Lin et al., 2016)) and Brown Tsaiya ducks (1 $270 \pm 136 \mathrm{~g}$ at 16 weeks (Tai et al., 1989)). The expected higher BW of males than females were also observed in other breeds (Tai and Rouvier, 1998; Téguia et al., 2008; Kaewtapee et al., 2018).

In the current study, six models were selected based on their popularity in poultry research and the AIC and BIC were used because of their excellent performance in non-linear models comparison. The AIC and BIC values indicated that the four-parameter models did not outperform the three-parameter models, and the Gompertz model (a three-parameter model) was the best. This result was different from the results obtained by Maruyama et al. (2001) who reported better performances for four-parameter models than the Gompertz model in several Pekintype ducks. In another study, which compared the non-linear models and spline regression models for describing the mule duck growth, Vitezica et al. (2010) stated that the Weibull model was the best. 
This inconsistency is possibly due to the sample size, genetics and management. The Bridges and Janoschek models performed similarly in the current studies, which was also reported previously (Kaewtapee et al., 2011; García-Muñiz et al., 2019; Do and Miar, 2020). Due to lacking the inflection point, the Brody model had the worst performance, and the Brody growth curve was also less overlapped with the actual BW curve (Figure 1). Therefore, the Brody model is not appropriate for evaluation of the growth performance in ducks. Nevertheless, despite the variety of existing growth models, the Gompertz model is a preferred model for evaluation of the growth curve in this duck breed.

The estimated asymmetric weights $(\alpha)$ for the duck were varied among models but generally, they were lower than values reported for other duck breeds (Vitezica et al., 2010; Kaewtapee et al., 2011; 2018). For instance, the estimated $\alpha, 1221 \pm 11.6 \mathrm{~g}$, obtained from the Gompertz model for male ducks was much lower than the estimated values, which ranged from $3.906 \mathrm{~g}$ to $4.047 \mathrm{~g}$, in other duck lines (Vitezica et al., 2010). Similarly, female ducks could reach the maximum weight of $1082 \pm 8.69 \mathrm{~g}$ according to the results of the Richards model, which are much lower than values obtained by Vitezica et al. (2010). These results simply indicate higher values of BW for the domesticated ducks than for Eastern spot-billed ducks.

The $\mathrm{k}$ values also varied among the models; very low values of $\mathrm{k}$ were obtained for Brody, Bridges and Janoschek models. Obtained $k$ values from the Gompertz model were 0.38 in males and 0.39 in females and were higher than values for the Anas platyrhynchos duck species (Knížetová et al., 1995). The mature rate is important for the farmers to decide the management strategies; therefore, future studies require exploring biology underlying the growth and mature rate of the Eastern spotbilled ducks. The age and weight at the inflection point for Eastern spot-billed duck were in the range of the previous studies in other duck species. The age at the inflection point in the current study as 3.48 weeks ( 24.6 days) to 3.58 weeks (25.06 days) were similar to the values of 22.5 days to 29.6 days for different types of ducks (Maruyama et al., 2001) or 25.5 for the Anas platyrhynchos duck species (Knížetová et al., 1995). The variation among the results obtained in different studies might be caused by applying different growth models, genetic variance among breeds, the use of feeds with different formulas and various raising environment.

\section{Conclusions}

The possibility of using the Gompertz growth model for modelling the growth of the Eastern spotbilled ducks was shown. Obtained information on the growth characteristics of the Eastern spot-billed ducks in the current study might be used for management strategies and further genetic or genomic research in this species.

\section{Conflict of interest}

The Authors declare that there is no conflict of interest.

\section{References}

Cherry P., Morris T.R. (Editors), 2008. Domestic Duck Production: Science and Practice. CABI. Wallingford (UK), https://doi. org/10.1079/9780851990545.0000

Do D.N., Miar Y., 2020. Evaluation of growth curve models for body weight in American mink. Animals 10, 22, https://doi. org/10.3390/ani10010022

FAOSTAT, 2021. FAOSTAT: Livestock primary, production quantity, duck meat, 2019. URL: http://www.fao.org/faostat/en/data/QL [access: February 20, 2021]

García-Muñiz J.G., Ramírez-Valverde R., Núñez-Domínguez R., Hidalgo-Moreno J.A., 2019. Dataset on growth curves of Boer goats fitted by ten non-linear functions. Data in Brief 23, 103672 , https://doi.org/10.1016/j.dib.2019.01.020

Kaewtapee C., Khetchaturat C., Bunchasak C., 2011. Comparison of growth models between artificial neural networks and nonlinear regression analysis in Cherry Valley ducks. J. Appl. Poult. Res. 20, 421-428, https://doi.org/10.3382/japr.2010-00223

Kaewtapee C., Prahkarnkaeo K., Bunchasak C., 2018. Effect of sex on growth curve, production performance and carcass quality of Cherry valley ducks. J. Appl. Anim. Res. 11, 9-18

Kaplan S., Gürcan E.K., 2018. Comparison of growth curves using non-linear regression function in Japanese quail. J. Appl. Anim. Res. 46, 112-117, https://doi.org/10.1080/09712119.2 016.1268965

Knížetová H., Hyánek J., Hyánková L., Bělíček P., 1995. Comparative study of growth curves in poultry. Genet. Sel. Evol. 27, 365, https://doi.org/10.1186/1297-9686-27-4-365

Lin R.L., Chen H.P., Rouvier R., Marie-Etancelin C., 2016. Genetic parameters of body weight, egg production, and shell quality traits in the Shan Ma laying duck (Anas platyrhynchos). Poult. Sci. 95, 2514-2519, https://doi.org/10.3382/ps/pew222

Maruyama K.,Vinyard B., Akbar M.K., Shafer D.J., Turk C.M., 2001. Growth curve analyses in selected duck lines. Br. Poult. Sci. 42, 574-582, https://doi.org/10.1080/00071660120088380

Minh D.V., Lindberge J.E., Ogle B., 2006. Effect of season and location on the crop and contents of local and improved scavenging hens in Northern Vietnam. Trop. Anim. Health Prod. 38, 121-129, https://doi.org/10.1007/s11250-006-4358-8

Pham L.D., Do D.N., Nam L.Q., Ba N.V., Ninh P.H., Thuy D.P., Son P.V., Thieu P.C., 2021. Evaluation of genetic diversity and population structure in four indigenous duck breeds in Vietnam. Anim. Biotechnol., https://doi.org/10.1080/1049539 8.2020.1868485 
R Development Core Team, 2011. R: A language and environment for statistical computing. R Foundation for Statistical Computing. Vienna (Austria)

Tai C., Rouvier R., 1998. Crossbreeding effect on sexual dimorphism of body weight in intergeneric hybrids obtained between Muscovy and Pekin duck. Genet. Sel. Evol. 30, 163, https:// doi.org/10.1186/1297-9686-30-2-163

Tai C., Rouvier R., Poivey J.P., 1989. Genetic parameters of some growth and egg production traits in laying Brown Tsaiya (Anas platyrynchos). Genet. Sel. Evol. 21, 377, https://doi. org/10.1186/1297-9686-21-3-377
TCN654, 2005. Complete feeds for broiler ducks (in Vietnamese), https://vanbanphapluat.co/10-tcn-654-2005-thuc-an-honhop-hoan-chinh-cho-vit-thit [access: January, 2020]

Téguia A., Ngandjou H.M., Defang H., Tchoumboue J., 2008. Study of the live body weight and body characteristics of the African Muscovy duck (Caraina moschata). Trop. Anim. Health Prod. 40, 5-10, https://doi.org/10.1007/s11250-007-9030-4

Vitezica Z.G., Marie-Etancelin C., Bernadet M.D., Fernandez X., RobertGranie C., 2010. Comparison of nonlinear and spline regression models for describing mule duck growth curves. Poult. Sci. 89, 1778-1784, https://doi.org/10.3382/ps.2009-00581 